\title{
Motivos do abuso de substâncias psicoativas por mulheres assistidas em Centro de Atenção Psicossocial
}

\author{
Motives of abuse of psychoactive substances by women assisted \\ in a Psychosocial Attention Center \\ Motivos del abuso de sustancias psicoativas por mujeres asistidas \\ en Centro de Atención Psicosocial
}

\section{Keity Laís Siepmann Soccol ${ }^{\mathrm{a}}$ Marlene Gomes Terra ${ }^{b}$ Stela Maris de Mello Padoin ${ }^{b}$ Danilo Bertasso Ribeiroc \\ Daiana Foggiato de Siqueira ${ }^{d}$ Janaina Lunardi Canabarro ${ }^{e}$}

\section{Como citar este artigo:}

Soccol KLS, Terra MG, Padoin SMM, Ribeiro DB, Siqueira DF, Canabarro JL. Motivos do abuso de substâncias psicoativas por mulheres assistidas em Centro de Atenção Psicossocial. Rev Gaúcha Enferm. 2018:39:e20170281. doi: https://doi. org/10.1590/1983-1447.2018.20170281
- Universidade Franciscana (UFN), Curso de Enfermagem. Santa Maria, Rio Grande do Sul, Brasil.

b Universidade Federal de Santa Maria (UFSM), Programa de Pós-graduação em Enfermagem. Santa Maria, Rio Grande do Sul, Brasil.

' Universidade Estadual do Oeste do Paraná (UNIOESTE), Departamento de Enfermagem, Curso de Enfermagem. Cascavel, Paraná, Brasil.

¿ Universidade Regional Integrada do Alto Uruguai e das Missões (URI), Curso de Enfermagem. Santiago, Rio Grande do Sul, Brasil.

e Sistema de Ensino Gaúcho (SEG), Escola técnica. Santa Maria, Rio Grande do Sul, Brasil.

\section{RESUMO}

Objetivo: Compreender os motivos atribuídos por mulheres ao abuso de substâncias psicoativas.

Método: Abordagem qualitativa de natureza fenomenológica. Foram entrevistadas 12 mulheres usuárias de substâncias psicoativas em tratamento no Centro de Atenção Psicossocial álcool e drogas, no Sul do Brasil. As entrevistas foram realizadas entre maio e junho de 2013. Os dados foram interpretados à luz da Fenomenologia Social de Alfred Schütz.

Resultados: 0 abuso de substâncias psicoativas é motivado pela influência das pessoas com as quais as mulheres mantêm um relacionamento ou com as quais conviveram. Ainda, as perdas e os conflitos familiares vivenciados também foram como um estopim para 0 abuso de substâncias psicoativas.

Conclusão: A assistência à saúde das mulheres necessita atender além das demandas, na medida em que deve levar em consideração a história de vida dessas mulheres.

Palavras-chave: Serviç̧os de saúde mental. Transtornos relacionados ao uso de substâncias. Transtornos relacionados ao uso de álcool. Mulheres.

\section{ABSTRACT}

Objective: To understand the reasons attributed by women to the abuse of psychoactive substances.

Method: Qualitative approach of phenomenological nature. We interviewed 12 women users of psychoactive substances under treatment at the Center for Psychosocial Care alcohol and drugs in Southern Brazil. The interviews were conducted between may and june 2013. The data were interpreted in light of Alfred Schütz's Social Phenomenology.

Results: The abuse of psychoactive substances is motivated by the influence of the people with whom the women have a relationship or with whom they have lived. Still, the losses and the family conflicts experienced were also a trigger for the abuse of psychoactive substances.

Conclusion: Women's health care needs to meet beyond demands, since they must take into account the life history of these women. Keywords: Mental health services. Substance-related disorders. Alcohol-related disorders. Women.

\section{RESUMEN}

Objetivo: Comprender los motivos que las mujeres atribuyen al abuso de sustancias psicoactivas.

Método: Enfoque cualitativo de naturaleza fenomenológica. Se entrevistaron a 12 mujeres usuarias de sustancias psicoactivas en tratamiento en el Centro de Atención Psicosocial al cohol y drogas, en el Sur de Brasil. Las entrevistas se realizaron entre mayo y junio 2013. Los datos fueron interpretados a la luz de la Fenomenología Social de Alfred Schütz.

Resultados: El abuso de sustancias psicoactivas es motivado por la influencia de las personas con las que las mujeres mantienen una relación o con las que conviven. Además, las pérdidas y los conflictos familiares vivenciados también fueron como un estopim para el abuso de sustancias psicoactivas.

Conclusión: La asistencia a la salud de las mujeres necesita atender más allá de las demandas, en la medida en que debe tener en cuenta la historia de vida de esas mujeres.

Palabras clave: Servicios de salud mental. Trastornos relacionados con sustancias. Trastornos relacionados con alcohol. Mujeres. 


\section{—INTRODUÇÃO}

As substâncias psicoativas são consideradas drogas que têm a capacidade de alterar o comportamento, o humor, a consciência e a cognição, agindo no sistema nervoso central(1). O consumo de substâncias psicoativas tem sido considerado como um problema social que acomete as pessoas independentemente de grupos étnicos, sexo, religião, classe social e escolaridade(2).

Além disso, é um tema relevante, pois há uma preocupação mundial com o número de pessoas que fazem uso de substâncias psicoativas com repercussão nos próprios indivíduos e também na sociedade ${ }^{(3)}$. Em 2013, cerca de 246 milhões de pessoas da população mundial, entre 15 e 64 anos de idade, usaram alguma substância psicoativa, neste caso, uma droga ilícita ${ }^{(4)}$. O abuso dessas substâncias ocasiona prejuízos físicos e emocionais para os usuários, além de interferir diretamente nas suas relações sociais, com o surgimento de problemas no ambiente familiar, escolar e profissional(5-6).

Pesquisa Nacional acerca do perfil dos consumidores de álcool e outras drogas mostrou que o uso dessas substâncias continua crescendo, havendo um aumento considerável no padrão de consumo entre as mulheres ${ }^{(7)}$. Ademais, esse estudo ressaltou que o início do uso ocorre precocemente e indicou o risco aumentado para a dependência da substância.

Mesmo que haja diferenças entre homens e mulheres no que diz respeito ao abuso de substâncias psicoativas, na medida em que este é maior entre os homens e são eles que, predominantemente, marcam presença em cenas de tráfico de entorpecentes, as mulheres são alvo de crescente investigação científica devido à maior vulnerabilidade física aos efeitos negativos da substância e devido às questões psicossociais do consumo feminino ${ }^{(5)}$.

As mulheres que abusam de substâncias psicoativas podem apresentar, com maior frequência, episódios depressivos, psicóticos, transtornos de personalidade e de ansiedade ${ }^{(5)}$. Ainda, ficam expostas a doenças e agravos acarretando implicações econômicas e políticas ${ }^{(2)}$.

Diante das consequências que o abuso dessas substâncias ocasiona na saúde da mulher, torna-se imprescindível aprofundar e desenvolver mais estudos com vistas a contribuir com o seu cuidado ${ }^{(8)}$, pois é preciso que haja uma superação das dimensões biomédicas pelos profissionais da área da saúde, para que compreendam o processo saúde/doença a fim de atender as suas especificidades ${ }^{(2)}$. Entre essas, o fato de que as mulheres usam as substâncias em locais privados devido ao constrangimento e à estigmatização que lhes são impostas ${ }^{(7)}$.
Ainda, destaca-se que a maioria da produção cientíica aborda o perfil dos usuários de drogas, fazendo comparações do uso entre homens e mulheres ${ }^{(9-10)}$, bem como estuda os fatores de risco que levam ao uso ${ }^{(11-12)}$ e os fatores de proteção(13). Nesse sentido, este estudo, além de ampliar o conhecimento acerca desse fenômeno, também permite compreender as motivações das mulheres que abusam de substâncias psicoativas para que, assim, possam ser pensadas estratégias na assistência à saúde delas, de acordo com as suas particularidades.

Diante da necessidade de compreender algumas das especificidades das mulheres usuárias, tem-se como objetivo compreender os motivos atribuídos por mulheres ao abuso de substâncias psicoativas.

\section{口 METODOLOGIA}

Pesquisa na abordagem qualitativa, de natureza fenomenológica, proveniente da dissertação de mestrado(14) e sob a luz do referencial de Alfred Schütz ${ }^{(15)}$. O cenário foi um Centro de Atenção Psicossocial álcool e drogas (CAPS Ad), de um município do interior do Estado do Rio Grande do Sul (RS), Brasil, cujo atendimento ocorreu por meio de uma equipe multiprofissional a pessoas usuárias de álcool e outras drogas, com o objetivo de garanti-las a reinserção social.

As participantes foram 12 mulheres usuárias de substâncias psicoativas com idades entre 25 e 56 anos em tratamento no CAPS Ad. O acesso a essas mulheres ocorreu por conveniência. Abordou-se aquelas que estavam participando de alguma atividade ou que vinham para consultas médicas. Em alguns momentos telefonava-se, por indicação da equipe, visando agendar um horário com as mulheres.

Como critérios de inclusão, elegeu-se as mulheres maiores de 18 anos, que não estivessem sob efeito de substância psicoativa e que estivessem realizando tratamento no serviço. De outro modo, como critérios de exclusão, não foram eleitas mulheres que apresentavam limitações na comunicação. No que concerne ao número de participantes, este não foi previamente determinado, pois o estudo fenomenológico considera a essência do que se mostra e não o número de entrevistas realizadas ${ }^{(16-17)}$. Após se chegar às participantes, não houve exclusão de nenhuma delas.

A coleta de dados foi realizada somente por uma pesquisadora, no período de maio a junho de 2013, em uma sala no CAPS Ad, de modo que se preservasse as identidades, bem como a confidencialidade das informações fornecidas pelas mulheres. A coleta ocorreu por meio de entrevista fenomenológica, com uso de gravador digital. A variação temporal das entrevistas oscilou entre 50 e 75 minutos. 
Empregou-se um roteiro que versava sobre a situação biográfica das mulheres e apresentava a seguinte questão aberta, a qual possibilitou que expressassem espontaneamente as suas vivências: quais os motivos que te levaram ao abuso de substâncias psicoativas (álcool ou outra)? Nesta perspectiva, as entrevistas foram encerradas quando se alcançou a suficiência de significados que fossem convergentes ao objetivo do estudo. Por isso, a análise foi concomitante à etapa de campo ${ }^{(17)}$.

Foi assegurado às participantes o sigilo das informações e o anonimato pela adoção da letra M (Mulher) seguida do número correspondente à ordem em que foi realizada a entrevista (M1, M2, M3) e assinatura do Termo de Consentimento Livre e Esclarecido (TCLE).

Para análise dos dados, após a transcrição das entrevistas, iniciou-se a leitura do texto para captar os motivos do abuso de substâncias atribuídos pelas mulheres. Houve a identificação das categorias concretas que abrigam o ato dos sujeitos. E, por fim, agrupou-se o significado da ação das mulheres, com a descrição do típico dos motivos do abuso de substâncias psicoativas por esse grupo social. Após, os dados foram interpretados sob a óptica da Fenomenologia Social de Alfred Schütz ${ }^{(15)}$.

O protocolo do projeto de pesquisa foi aprovado pelo Comitê de Ética em Pesquisa com Seres Humanos, da Universidade Federal de Santa Maria, Parecer № 245.218, respeitando, assim, os preceitos éticos da Resolução do Conselho Nacional de Saúde № 466/2012.

Este estudo está fundamentado na Fenomenologia Social de Alfred Schütz, que contempla um arcabouço teórico convergente com o objetivo de compreender os motivos do abuso de substâncias psicoativas por mulheres. Para Schütz, as pessoas agem em um mundo, entendido como o mundo da vida, no qual estabelecem diferentes relações sociais. Também afirma que as pessoas agem de acordo com a sua situação biográfica e com o seu estoque de conhecimento ${ }^{(15)}$.

A situação biográfica de um indivíduo compreende todo o momento de sua vida, suas experiências vividas anteriormente, em que o conteúdo e a sequência dessas experiências são exclusivos dele no mundo da vida. Ao viver nesse mundo, os indivíduos possuem um estoque de conhecimento, que é a sedimentação de todas as suas experiências prévias, organizadas como uma posse que está facilmente disponível, trata-se de algo que é dado a ele e somente a ele ${ }^{(15)}$.

De acordo com Schütz, as pessoas agem no mundo da vida tendo em mente seus próprios propósitos e objetivos, que, por sua vez, estão enraizados em seu passado, na história singular de vida de cada um, atribuindo, assim, um significado às suas ações. Ao apreender as ações em comum desse grupo social, formam-se as categorias concretas do vivido, que são construídas a partir dos depoimentos das mulheres ${ }^{(15)}$.

Esse referencial permite, por meio da compreensão da ação, identificar os motivos que levam as pessoas a agirem no mundo. Mundo esse que é social, vivenciado por atores sociais junto aos seus semelhantes ${ }^{(15)}$. Buscou-se a compreensão dos motivos: porque?. Esses motivos são aqueles objetivos, relacionados ao passado. Assim, buscou-se compreender os motivos que fizeram com que as mulheres abusassem de substâncias psicoativas.

Somente após a compreensão dos motivos da ação chega-se ao típico da ação, ou seja, à identificação da estrutura comum dos significados atribuídos pelo grupo social a certa ação ${ }^{(15)}$.

\section{口ESULTADOS E DISCUSSÃO}

Desvelaram-se duas categorias concretas do vivido: 1) Influências das relações sociais para o uso/abuso de substâncias psicoativas; 2) Perdas e conflitos familiares como motivo para o abuso de substâncias psicoativas.

\section{Influências das relações sociais para o uso/ abuso de substâncias psicoativas}

Nesta categoria observa-se a presença de motivos representados pelas influências sociais sejam elas da família, dos companheiros ou das amizades para o início do uso, que com o passar do tempo, levou essas mulheres ao abuso. Nesse sentido, revela-se a influência da família para o uso de substâncias psicoativas:

Eu comecei a beber tinha 8 anos de idade. Eu ia buscar bebida para minha mãe, cachaça. [...] provava. [...] pelos 13 anos já estava viciada.(M1)

Comecei com 14 anos.[...] hoje, não deixo meus sobrinhos nem experimentarem. (M3)

As mulheres cresceram nessa realidade considerando o uso de substâncias psicoativas como algo construído social e culturalmente. Esse costume constitui a herança social que é transmitida às crianças que nascem e crescem dentro do grupo ${ }^{(15)}$. É comum a presença de outro familiar com abuso de álcool quando se investiga mulheres usuárias de substâncias psicoativas ${ }^{(5)}$.

Elas iniciaram o uso de substâncias psicoativas por influência da família, mãe e demais familiares, uma ação so- 
cial que foi vivenciada desde a infância, por meio da convivência com seus antecessores que também faziam uso. A família pode ser considerada como um fator de risco para o uso de substâncias psicoativas ${ }^{(18)}$, quando um estudo com 519 usuários de crack evidencia que 48,3\% referiram já ter usado drogas ou compartilhado com algum familiar.

Observa-se também a influência de semelhantes para o abuso de substâncias psicoativas, como dos companheiros, namorados ou maridos:

Até os 20 anos nem beber eu bebia, comecei depois dos 20 . Depois que eu me juntei, o meu marido bebia assim, mas, normal também. Tomava uma caipira, só que daí eu fui aprendendo a tomar junto com ele, foi, foi e eu fui tomando mais. (M5)

Bem no final, eu acabei me envolvendo com uma pessoa que era traficante. Ele não usava, mas vendia. Então, isso foi o que realmente acabou comigo. E antes dele, os namorados que eu tive também usavam. (M8)

[...]eu sabia me controlar e, às vezes, até eu brigava com o pai do meu filho porque em vez de me levar alguma coisa pra comer ele me levava droga. Então, muitas vez, a gente brigava por causa disso. (M10)

A influência para o uso de substâncias psicoativas pelas mulheres ocorreu devido ao estabelecimento de relacionamentos amorosos com semelhantes que também usavam. Esse dado vai ao encontro de um estudo, realizado com mulheres usuárias de crack, que evidenciou que essas iniciam o consumo a partir da influência de uma pessoa do seu ciclo social, geralmente alguém do sexo masculino ${ }^{(19)}$.

As mulheres, ao dividirem o tempo e o espaço com pessoas que também usavam substâncias psicoativas, estabeleceram com esses relações de familiaridade. Assim sendo, o convívio com outros usuários é um potente influenciador na rede de motivações dessas mulheres.

Além disso, as mulheres expressaram as amizades como uma influência ao uso da substância psicoativa:

Beber mesmo foi na adolescência. Quando eu comecei a sair para noite com meus amigos. Eu bebia todo fim de semana e foi indo, até chegar na droga, na maconha, daí foi indo. [...].. Eu comecei beber por amizade, por influência. (M3)

A gente estava num posto de gasolina, com umas amigas e uma delas usou e disse: "Experimenta!" Eu digo: não! Experimenta! [...]ali começou. (M8)
Eu comecei a usar estava com os amigos. Cheguei numa casa lá onde eu estava lá. Lá era só usuário e coisarada e eu fui vendo, e eles vinham me oferecendo e eu dizendo que não, e foi, foi que...morando ali ... no mesmo lugar... aí fui experimentar pela primeira vez, fiquei um ano usando. (M10)

O uso de substâncias psicoativas por mulheres está associado com o desejo de inserir-se, ser aceita e respeitada socialmente ou então por pressão de um determinado grupo social. Os amigos podem exercer influência na busca de novas experiências, inclusive sobre o uso de drogas ${ }^{(20)}$. Isso mostra o significado subjetivo que o grupo social tem para seus membros, que se expressa por um sentimento de pertencimento, de compartilhamento de interesses comuns ${ }^{(15)}$.

Diante do exposto, observa-se a influência que as relações sociais exercem sobre as motivações que levam ao abuso de substâncias psicoativas pelas mulheres. Nesse sentido, o uso de substâncias psicoativas exige dos profissionais de saúde uma compreensão que vá além do processo saúde/doença, mas que entenda o papel da mulher na sociedade, bem como as relações sociais que elas estabelecem ${ }^{(2)}$.

Nas situações referenciadas pelas mulheres, destacou-se a influência das relações sociais, em que as famílias, os companheiros e as amizades assumiram um papel importante quanto à motivação para o uso e para o abuso de substâncias psicoativas.

\section{Perdas e conflitos familiares como motivo para o abuso de substâncias psicoativas}

As mulheres ao direcionarem seu olhar para o passado, com o intuito de compreender os motivos do abuso de substâncias psicoativas expressaram que esses estão relacionados às diversas perdas e às relações familiares conflituosas que vivenciaram em seu mundo da vida.

Essas perdas que as levaram ao abuso de substâncias psicoativas, foram motivadas devido à morte de seus semelhantes, ao afastamento do convívio do pai, à traição do companheiro e à perda de seus sonhos, bem como às perdas financeiras. É no mundo da vida que as pessoas nascem e estabelecem suas relações sociais. Essas acontecem de acordo com a relação que as pessoas mantêm com os semelhantes, sendo que os antecessores são aqueles com quem elas já tiveram um compartilhamento de tempo e espaço em seu passado, os sucessores são aqueles com quem elas gostariam de ter e os contemporâneos são aqueles com quem elas mantêm no momento ${ }^{(15)}$. 
Eu me afundei mais no álcool, depois que meu filho faleceu. Pois eu sinto uma dor que não passa. [...]A dor é tão grande. Que parece que eu não vou suportar. Não existe dor maior que perder um filho.[...] A vida perdeu sentido para mim[.... (M2)

Perda da minha mãe, depois eu perdi meu bebê. Nesse ano, eu comecei a aumentar a quantidade de bebida, eu bebia em casa e escondida do meu marido. E daí deu um ano e a gente se separou. [...] muito difícil daí começou a piorar cada vez mais, assim, perdi minha mãe, perdi meu bebê, me separei. (M3)

Eu comecei a beber mesmo com 19 anos, quando a minha filha faleceu, que foi horrivel pra mim, que eu não aceiteie ai sim eu comecei a beber[...]. (M11)

O mundo da vida das mulheres foi permeado por relacionamentos sociais com diferentes tipos de semelhantes, com os quais essas compartilharam vivências e experiências que foram se modificando ao longo do tempo. As situações vividas no contexto familiar e as relações sociais contribuíram para que as mulheres escolhessem seguir alguns caminhos ao longo das suas vidas, dentre esses caminhos, encontra-se o abuso de substâncias. As relevâncias intrínsecas são resultados de nossos interesses escolhidos, estabelecidos por nossa decisão espontânea. Assim, as situações de perdas vivenciadas pelas mulheres no mundo da vida influenciaram nas suas escolhas ${ }^{(15)}$.

No que tange aos relacionamentos amorosos, as mulheres, ao se recordarem de suas experiências, relatam que essas são alguns dos motivos que as levaram ao abuso de substâncias. Isso mostra o quanto o fracasso em um relacionamento amoroso pode influenciar nas escolhas, decisões e ações dessas mulheres que emergem do seu mundo da vida.

As pessoas vivem em um mundo onde buscam ocupar uma posição, não apenas em termos do espaço físico e do tempo exterior, mas também de seu papel no sistema social, de sua posição moral e ideológica. Além disso, as experiências que as pessoas vivenciam nesse mundo podem deixar marcas(15).

Entre as lembranças desse mundo que deixaram marcas na vida das mulheres, estão as marcas de uma vida acompanhada por perdas e dificuldades financeiras:

A minha infância foi boa, só que nós éramos muito pobres. Meu pai era agricultor. Ele foi a falência. Foi muito triste isso! E a mãe trabalhava vendendo (produtos de beleza de revistas) que tinha na época, para nos alimentar e para dar estudo para gente. (M12)
Eu comecei a tomar mesmo quando eu fiquei desiludida com os papéis da minha aposentadoria, que não deu certo. Quando a gente casou, a gente passou muito trabalho entendeu? [...]Passamos fome também. (M9)

As mulheres, ao recordarem dessas marcas de uma infância pobre e sofrida e por possuírem uma vida adulta acompanhada por dificuldades financeiras, atribuíram a isso como sendo algumas das motivações que as levaram ao abuso de substâncias psicoativas. O estoque de conhecimento dessas mulheres revelou uma situação biográfica conturbada, na qual estiveram presentes diversas motivações que as levaram ao abuso de substâncias psicoativas. Viver no mundo da vida cotidiana significa viver em um envolvimento interativo com muitas pessoas, em complexas redes de relacionamentos sociais ${ }^{(15)}$.

Ao compreender os motivos atribuídos pelas mulheres ao abuso de substâncias psicoativas em seu mundo da vida, observa-se que a situação biográfica delas foi marcada por diversas perdas em suas relações sociais. Pode-se afirmar que há uma forte influência de seu passado histórico cultural interferindo nas suas condutas e ações.

No que tange ao passado histórico cultural das mulheres, estas experienciaram relações familiares conflituosas (agressões sofridas no passado pelos familiares e no presente por seus companheiros), que são expressas pela sua situação biográfica:

Eu era muito mal tratada (agredida) pela mãe. Minha mãe era alcoólatra também, bebia muito, eu fugi de casa. Quando eu saí de casa, comecei a fumar cigarro, comecei a beber e a usar drogas[...] A minha mãe me tirou todos os meus sonhos. (M4)

Ela (mãe) me criou abaixo de pancada. Ela foi uma pessoa assim, muito estúpida. E até eu não culpo muito ela também porque ela foi criada assim.[...] E a minha mãe era assim, enquanto ela não via sangue ela não parava de bater. (M6)

A relação de superioridade dos pais em relação aos filhos mostra a maneira rígida e disciplinar em que essas mulheres, no período da infância e da adolescência, foram criadas, sendo subordinadas conforme a hierarquia social. Nesse aspecto a organização do mundo social constitui a realidade social nas pessoas que nele vivem. Mundo este que não é simplesmente físico, mas também um mundo sociocultural e nele encontram-se hierarquias de superioridade e subordinação, de líder e seguidores, daqueles que comandam e daqueles que obedecem ${ }^{(15)}$. 
As mulheres, após saírem de suas famílias de origem e formarem novos vínculos familiares, passaram a ser agredidas também por seus companheiros:

Eu tenho problemas em casa. Eu já fui casada. Sofri violência. [...]Então, desde novinha eu saía para rua, meus irmãos me batiam [...](M7)

Muitas vezes, ele (marido) vinha me humilhar. Teve uma noite mês passado, que eu trabalhei de noite. [...] Ele achava que saia com as colegas para tomar cerveja, não sei. Eu saia de lá pingando de suor. Louca para chegar em casa tomar um banho. Como é que vou sair? Eu não sou de sair beber junto com colega. Nunca fui disso. (M9)

Ele (marido) bebia demais também. Eera muito ciumento. Ele via coisa onde não tinha. Teve uma vez que ele pegou e ficou brabo comigo e me deu (bateu) em mim[...] É horrível! (M10)

A situação biográfica dessas mulheres foi permeada por agressão e conflitos, vivenciando desde a sua infância até a vida adulta essas condições. Isto mostra a relação de superioridade dos semelhantes e contemporâneos sobre as mulheres nas relações sociais. As agressões sofridas pelas mulheres nas relações sociais do seu mundo da vida foram expressas como sendo os motivos atribuídos ao abuso de substâncias. As situações disparadoras para o abuso de susbtâncias psicoativas estão associadas às mudanças nos papéis sociais, como a presença de brigas, traição e violência( ${ }^{(5)}$.

Em suma, o mundo da vida dessas mulheres foi constantemente permeado por dificuldades nas relações sociais, manifestadas pela falta de afetividade e de estabelecimento de vínculos, também por perdas, agressões e dificuldades financeiras. Essas situações vivenciadas pelas mulheres em seu mundo da vida são os motivos (porque?) que as levaram ao abuso de substâncias psicoativas.

O típico da ação desse grupo social mostra que as muIheres abusam de substâncias psicoativas devido às influências das relações sociais e devido às perdas e aos conflitos familiares.

\section{— CONCLUSÃO}

Este estudo mostrou que os motivos atribuídos pelas mulheres ao abuso de substâncias psicoativas estão relacionados às influências das pessoas com as quais as muIheres conviveram, bem como se devem às perdas e aos conflitos que vivenciaram no seu mundo da vida.
No que tange à influência das famílias de origem das mulheres, observa-se as dificuldades nas relações, a falta de afetividade e de vínculo que repercutiram e influenciaram nas suas escolhas favorecendo, desse modo, um ciclo vicioso do uso de drogas.

Quanto à situação conjugal, a convivência com companheiros que abusam de substâncias é fator preponderante para a exposição das mulheres às situações de violência. Portanto, cabe aos profissionais da área da saúde atentar para os sinais objetivos (visíveis) e subjetivos (invisíveis) da violência, com vistas a proporcionar uma escuta ativa no sentido de discutir as formas de enfrentamento dessa situação. Ao implementar um cuidado ampliado, os profissionais de saúde poderão contribuir com a proteção dessas mulheres e com a promoção de sua saúde.

Também é fundamental que a equipe multiprofissional atenda as demandas dessas mulheres e, de modo conjunto, desenvolva um planejamento vislumbrando a possibilidade de romper com hábitos e costumes que Ihes foram transmitidos, de aceitação do uso e abuso de substâncias, discutindo seu contexto vivencial, sua situação biográfica e bagagem de conhecimentos, estimulando-as a refletir, projetar e agir de forma a buscar uma maneira de enfrentamento e de rompimento do abuso de substâncias.

Na prática clínica, sugere-se repensar sobre quais as necessidades dessas mulheres, bem como sobre qual é a melhor estratégia para uma assistência que atenda essas demandas para que o tratamento seja resolutivo.

O desenvolvimento deste estudo teve algumas limitações, sendo uma delas a dificuldade de acesso à população. Para tanto, foram adotadas estratégias como a realização de contatos telefônicos e de convites para participação em grupos e outras atividades no CAPS. Salienta-se que os estudos no tema de uso de substâncias psicoativas é vasto, no entanto, possuem foco na população de homens e na abordagem quantitativa, o que mostra a carência de estudos com a população de mulheres, sendo necessárias aproximações que podem servir de subsídio para o aprimoramento da atenção à saúde do público feminino. Assim, recomenda-se a ampliação e o aprofundamento dos estudos acerca do abuso de substâncias psicoativas nas relações sociais da população feminina.

\section{口 REFERÊNCIAS}

1. Santos MVF, Pereira DS, Siqueira MS. Uso de álcool e tabaco entre estudantes de Psicologia da Universidade Federal do Espírito Santo. J Bras Psiquiatr. 2013;62(1):22-30. doi: http://dx.doi.org/10.1590/5004720852013000100004 
2. Souza MRR, Oliveira JF, Nascimento ER. Women's health and the phenomenon of drugs in brazilian magazines. Texto Contexto Enferm. 2014;23(1):92-100. doi: https://doi.org/10.1590/S0104-07072014000100011.

3. Abarca AM, Pillon SC. Nursing students' perception regarding predicting facts of drug use. Rev Latino-Am Enfermagem. 2008;16(esp):607-13. doi: https://doi. org/10.1590/S0104-11692008000700017.

4. United Nations Office on Drugs and Crime (AU). World drug report 2017. Vienna: UNODC; 2017 [cited 2017 Dec 8]. Booklet 1- Executive summary: conclusions and policy implications. Available from: http://www.unodc.org/wdr2017/ field/Booklet_1_EXSUM.pdf.

5. Esper LH, Corradi-Webster CM, Carvalho AMP, Furtado EF. Women in outpatient treatment for alcohol abuse: sociodemographic and clinical characteristics Rev Gaúcha Enferm. 2013;34(2):93-101. doi: http://dx.doi.org/10.1590/S198314472013000200012.

6. Siqueira DF, Backes DS, Moreschi C, Terra MG, Soccol KLS, Souto VT. Social reintegration of crack addicts: actions taken by the Family. Texto Contexto Enferm. 2015;24(2):548-53. doi: https://doi.org/10.1590/0104-07072015001332014.

7. Bastos Fl, Bertoni N (organizadores). Pesquisa Nacional sobre o uso de crack: quem são os usuários de crack e/ou similares do Brasil? quantos são nas capitais brasileiras?. Rio de Janeiro: Editora ICICT/FIOCRUZ; 2014 [citado 2017 dez 7]. Disponível em: https://www.arca.fiocruz.br/handle/icict/10019.

8. Monteiro CFS, Silva Júnior FJG. 0 fenômeno das drogas no universo feminino. Rev Enferm UFPE on line. 2013 out [citado 2017 nov 10];7(esp). Disponivel em: https://periodicos.ufpe.br/revistas/revistaenfermagem/article/view/12238/14851.

9. Maehira Y, Chowdhury El, Reza M, Drahozal R, Gayen TK, Masud I, et al. Factors associated with relapse into drug use among male and female attendees of a three-month drug detoxification-rehabilitation programme in Dhaka, Bangladesh: a prospective cohort study. Harm Reduct J. 2013;10:14. doi: https://doi. org/10.1186/1477-7517-10-14.

10. Abulseoud OA, KarpyakVM, SchneeklothT, Hall-Flavin DK, Loukianova LL, Geske JR, et al. A retrospective study of gender differences in depressive symptoms and risk of relapse in patients with alcohol dependence. Am J Addict.2013;22(5):437-42. doi: https://doi.org/10.1111/j.1521-0391.2013.12021.x.
11. Moeeni M, Razaghi EM, Ponnet K, Torabi F, Shafiee SA, Pashaei T. Predictors of time to relapse in amphetamine-type substance users in the matrix treatment program in Iran: a Cox proportional hazard model application. BMC Psychiatry. 2016;16:265. doi: https://doi.org/10.1186/s12888-016-0973-8.

12. Schepis TS, Tapscott BE, Krishnan-Sarin S. Stress-related increases in risk taking and attentional failures predict earlier relapse to smoking in young adults: a pilot investigation. Exp Clin Psychopharmacol. 2016;24(2):110-9. doi: https:// doi.org/10.1037/pha0000066.

13. Majer JM, Jason LA, Aase DM, Droege JR, Ferrari JR. Categorical 12-step involvement and continuous abstinence at 2 years. J Subst Abuse Treat. 2013;44(1)4651. doi: https://doi.org/10.1016/j.jsat.2012.03.001.

14. Soccol KLS. Motivos atribuídos por mulheres ao abuso de substâncias psicoativas [dissertação]. Santa Maria (RS): Universidade Federal de Santa Maria; 2014 [citado 2017 out 10]. Disponível em: https://repositorio.ufsm.br/ handle/1/7409.

15. Schütz, A. Sobre fenomenologia e relações sociais. Petrópolis: Vozes; 2012.

16. Boemer MR. A condução de estudos segundo a metodologia de investigação fenomenológica. Rev Latino-Am Enfermagem.1994;2(1):83-94. doi: https:// doi.org/10.1590/S0104-11691994000100008.

17. Paula CC, Padoin SMM, Terra MG, Souza IEO, Cabral IE. Modos de condução da entrevista em pesquisa fenomenológica: relato de experiência. Rev Bras Enferm. 2014;67(3):468-72. doi: https://doi.org/10.5935/00347167.20140063.

18. Horta RL, Vieira LS, Balbinot AD, Oliveira GO, Poletto S, Teixeira VA. Influência da família no consumo de crack. J Bras Psiquiatr.2014;63(2):104-12. doi: https:// doi.org/10.1590/0047-2085000000013.

19. Cruz VD, Oliveira MM, Pinho LB, Coimbra VCC, Kantorski LP, Oliveira JF. Sociodemographic conditions and patterns of crack use among women. Texto Contexto Enferm. 2014;23(4):1068-76. doi: https://doi.org/10.1590/010407072014000580013

20. Marangoni SR, Oliveira MLF. Triggering factors for drug abuse in women.Texto Contexto Enferm. 2013;22(3):662-70. doi: https://doi.org/10.1590/S010407072013000300012

\section{Autor correspondente:}

Keity Laís Siepmann Soccol

E-mail:keitylais@hotmail.com
Recebido: 02.01.2018

Aprovado: 02.07.2018 